\title{
EFFEcts of Long-Term Oxygen TREATMEnt on $\alpha$-Ketoglutarate DeHYdrogenase ACTIVITY AND Oxidative Modifications IN Mitochondria of the Guinea Pig Heart
}

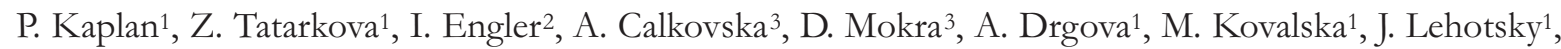 \\ D. Dobrota ${ }^{1}$
}

\begin{abstract}
${ }^{1}$ Department of Medical Biochemistry, Center of Excellence for Cardiovascular Research of the Slovak Academy of Sciences, Jessenius Faculty of Medicine, Comenius University, Martin, Slovakia; ${ }^{2}$ Department of Physiology, Medical Faculty, PJ Safarik University, Kosice, Slovakia; ${ }^{3}$ Department of Physiology, Jessenius Faculty of Medicine, Comenius University, Martin, Slovakia
\end{abstract}

\begin{abstract}
Objective: Oxygen therapy is used for the treatment of various diseases, but prolonged exposure to high concentrations of $\mathrm{O}_{2}$ is also associated with formation of free radicals and oxidative damage.

Methods: In the present study we compared $\alpha$-ketoglutarate dehydrogenase (KGDH) activity and mitochondrial oxidative damage in the hearts of guinea pigs after long-term (17 and $60 \mathrm{~h}$ ) oxygenation with $100 \%$ normobaric $\mathrm{O}_{2}$ and with partially negatively $\left(\mathrm{O}_{2 \text { neg }}\right)$ or positively $\left(\mathrm{O}_{2 \text { posit }}\right)$ ionized oxygen.

Results: Inhalation of $\mathrm{O}_{2}$ led to significant loss in $\mathrm{KGDH}$ activity and thiol group content and accumulation of bityrosines. Inhalation of $\mathrm{O}_{2}$ neg was accompanied by more pronounced KGDH inhibition, possibly due to additional formation of protein-lipid conjugates. In contrast, $\mathrm{O}_{2}$ posit prevented loss in $\mathrm{KGDH}$ activity and diminished mitochondrial oxidative damage. Conclusions: These findings suggest that oxygen treatment is associated with impairment of heart energy metabolism and support the view that inhalation of $\mathrm{O}_{2}$ posit optimizes the beneficial effects of oxygen therapy.
\end{abstract}

Key words: oxygenation, reactive oxygen species, $\alpha$-ketoglutarate dehydrogenase, heart, oxidative damage

\section{INTRODUCTION}

Oxygen therapy is applied for the treatment of various diseases and clinical conditions, including myocardial infarction [1]. The beneficial effects of increased oxygenation of plasma and body tissues are related to the stimulation of angiogenesis, anti-inflammatory response, and immune function [2]. On the other hand, it is well known that exposure to pure $\mathrm{O}_{2}$ is toxic and could cause serious tissue damage. Although the molecular mechanism by which hyperoxia affects body tissues is not completely understood, there is accumulating evidence that reactive oxygen/nitrogen species (ROS/RNS) are important factors mediating both beneficial and adverse effects of increased oxygenation $[2,3]$. Antioxidant supplementation was used to prevent negative impacts of oxygenation therapy, however, with contradictory results. While some studies have shown protective effects of exogenously administered antioxidants $[4,5]$ others have failed to demonstrate prevention against oxidative damage [6]. Recent studies from our laboratories have suggested that the adverse effects of classical oxygenation therapy on lungs are reduced when inhaled oxygen is partially ionized [7]. Long-term inhalation of partially positively ionized oxygen was associated with better surfactant activity, milder inflammatory response, and lower oxidative stress than inhalation of $\mathrm{O}_{2}$ or partially negatively ionized oxygen.

The aim of present study was to compare the role of long-term classical oxygenation with molecular oxygen and oxygenation with partially ionized oxygen in oxidative damage to the guinea pig heart. For this purpose, we measured the markers of lipid and protein modifications: conjugated dienes, thiol group content, bityrosines, and lysine conjugates with lipid peroxidation-end products in cardiac mitochondria. Furthermore, to evaluate the role of mitochondria in oxygenation-induced oxidative stress, the enzyme activity of $\alpha$-ketoglutarate dehydrogenase (KGDH), a key component of citric acid cycle was measured after different oxygenation treatments.

\section{MATERIAL AND Methods}

\section{Animals and Oxygenation Treatment}

All experiments were performed in accordance with the Guide for the Care and Use of Laboratory Animals published by The US National Institute of Health (NIH publication NO 85-23, revised 1996), and the ethical guidelines of the Jessenius Faculty of Medicine, Comenius University in Martin.

Forty male Trik guinea pigs (supplied by IEP SAS, Dobra Voda, Slovakia) weighing 250-350 g were used in the experiments. For oxygenation experiments, guinea pigs were placed in a sealed metabolic chamber and exposed for a period of 17 and $60 \mathrm{~h}$ to $100 \%$ molecular $\left(\mathrm{O}_{2} \mathrm{~mol}\right)$, partially negatively charged, $\cdot \mathrm{O}_{2}{ }^{-}$, $\left(\mathrm{O}_{2}\right.$ neg $)$ or partially positively charged, $\cdot \mathrm{O}_{2}{ }^{+},\left(\mathrm{O}_{2}\right.$ posit $)$ oxygen as described previously [7]. The $\mathrm{O}_{2}$ concentration was monitored periodically by an oxygen analyzer 
(Permolyt 3, Veb Junkalor, Germany). Partial and unipolar ionization of medical $\mathrm{O}_{2}$ was induced as described previously [8] between two electrodes with 15 $\mathrm{kV}$ using plasma chamber Oxygen Ion 3000/Dr. Engler (CStronic $\mathrm{GmBH}$, Austria) which is certified as medical therapeutic device. The control group inhaled atmospheric air.

\section{Preparation of Cardiac Mitochondria AND DETERMINATION OF KGDH ACTIVITY}

At the end of oxygenation treatment, a lethal dose of anesthetics was injected intraperitoneally. Hearts were excised, immediately washed with physiological solution, and stored at $-80^{\circ} \mathrm{C}$ until used. Mitochondrial fractions were isolated from thawed cardiac homogenates by differential centrifugation and sonication in water bath. KGDH activity was determined by monitoring $\mathrm{NAD}^{+}$reduction at $340 \mathrm{~nm}$ at $25^{\circ} \mathrm{C}$ [9]. Mitochondria $(50 \mu \mathrm{g}$ protein $/ \mathrm{ml})$ were incubated in medium containing $25 \mathrm{mM} \mathrm{K \textrm {K } _ { 2 }} \mathrm{PO}_{4}, 5 \mathrm{mM} \mathrm{MgCl}$, $0.5 \mathrm{mM}$ EDTA, $0.1 \%$ Triton $\mathrm{X}-100,40 \mathrm{mM}$ rotenone, $2.5 \mathrm{mM} \alpha$-ketoglutarate, $0.1 \mathrm{mM}$ coenzyme A, $0.2 \mathrm{mM}$ thiamine diphosphate and $1 \mathrm{mM} \mathrm{NAD}^{+}$at $\mathrm{pH} 7.25$.

\section{Determination of Lipid and Protein Oxidative}

\section{DAMAGE}

Formation of conjugated dienes was estimated from the absorbance ratio $A_{233 \mathrm{~nm}} / \mathrm{A}_{215 \mathrm{~nm}}$ of mitochondria (0.02 $\mathrm{mg}$ protein per $\mathrm{ml}$ ) dispensed in $10 \mathrm{mM}$ phosphate buffer containing 1\% Lubrol [10]. Total thiol group content was determined spectrophotometrically at $412 \mathrm{~nm}\left(\varepsilon=13.6 \mathrm{mM}^{-1} \mathrm{~cm}^{-1}\right)$ as described previously [10]. All fluorescence measurements were performed in solution containing $0.05 \mathrm{mg}$ of mitochondrial protein per $\mathrm{ml}, 10 \mathrm{mM}$ HEPES and $100 \mathrm{mM} \mathrm{KCl}$, $\mathrm{pH}=7.0$ at room temperature on a PerkinElmer LS 55 spectrophotofluorimeter, as shown previously [12]. The emission spectra of bityrosine, a product of tyrosine oxidation, were recorded in a range of 380-440 $\mathrm{nm}$ (5 nm slit width) at the excitation wavelength of $325 \mathrm{~nm}(5 \mathrm{~nm})$. The emission spectra (425-480 nm, 5 $\mathrm{nm}$ ) of lysine conjugates with LPO-end products were recorded at excitation of $365 \mathrm{~nm}(5 \mathrm{~nm})$.

\section{STATISTICAL ANALYSIS}

Data are expressed as means \pm SE. One-way analysis of variance with post-hoc comparisons by a StudentNeuman-Keuls test was carried out to test for differences among groups. A value of $\mathrm{p}<0.05$ was considered to be statistically significant.

\section{RESULTS}

Protein oxidative damage was assessed by the measurements of bityrosines and thiol group content. As shown in Fig. 1, 17- and 60-hour inhalations of $\mathrm{O}_{2}$ mol or $\mathrm{O}_{2}$ neg were associated with a significant accumulation of protein bityrosines. When compared with the control guinea pigs, which inhaled atmospheric air, the 17- and 60-hour $\mathrm{O}_{2}$ mol treatments increased bityrosines by $10.1 \%(\mathrm{p}<0.01)$ and $10.9 \%(\mathrm{p}<0.001)$, and

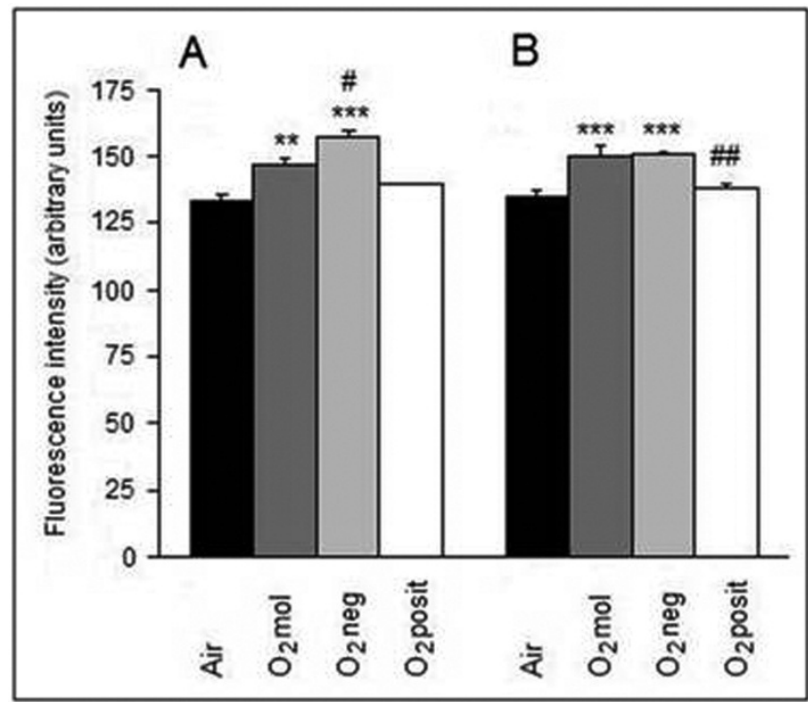

Fig. 1. Effects of $17 \mathrm{~h}(\mathrm{~A})$ and $60 \mathrm{~h}$ (B) oxygenation treatments on bityrosine formation in guinea pig cardiac mitochondria. Values are means $\pm \mathrm{SE}$ of 5 experiments. ${ }^{* *} \mathrm{P}<0.01$, $* * * \mathrm{P}<0.001$ - significantly different compared with the airtreated group; \# $\mathrm{P}<0.05$, \#\# $\mathrm{P}<0.01$ - significantly different when compared with the $\mathrm{O}_{2}$-treated group.

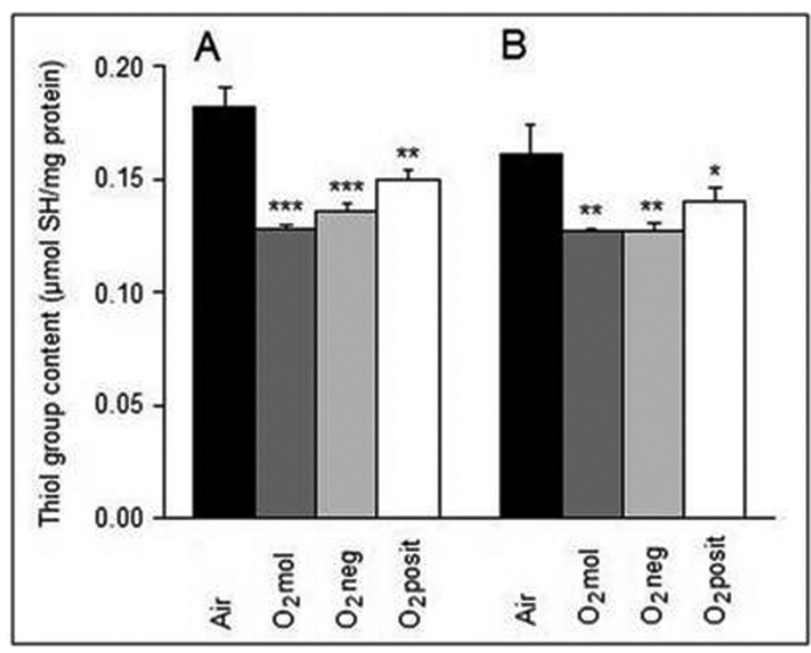

Fig. 2. Thiol group content in guinea pig cardiac mitochondria subjected to $17 \mathrm{~h}(\mathrm{~A})$ and $60 \mathrm{~h}$ (B) oxygenation treatments. Values are as means $\pm \mathrm{SE}$ of 5 experiments. $* \mathrm{P}<0.05$, $* * \mathrm{P}<0.01$, $* * * \mathrm{P}<0.001$ - significantly different compared with the air-treated group.

the $\mathrm{O}_{2}$ neg treatments increased bityrosines by $18.0 \%$ $(p<0.001)$ and $11.3 \%(p<0.001)$, respectively (Fig. 1). On the other hand, bityrosine content was unchanged by inhalation of $\mathrm{O}_{2}$ posit.

All kinds of oxygenation treatments used decreased the thiol group content, but to a different extend (Fig. 2). The $\mathrm{O}_{2}$ mol inhalation caused loss of thiols by $29.7 \%(p<0.01)$ and $21.1 \%(p<0.01)$ after 17 - and 60hour treatment, respectively. The $\mathrm{O}_{2 \text { neg }}$ inhalation resulted in decreases of thiols by $25.3 \%(p<0.01)$ and $21.1 \%(\mathrm{p}<0.01)$. Changes in $\mathrm{O}_{2}$ posit treated animals were lower $(17.6 \%, \mathrm{p}<0.01$ and $13.0 \%, \mathrm{p}<0.05)$, respectively. 
Table 1. Lipid and protein oxidative damage.

\section{Conjugated dienes Protein-LPO \\ A233nm/A215nm (arbitrary units)}

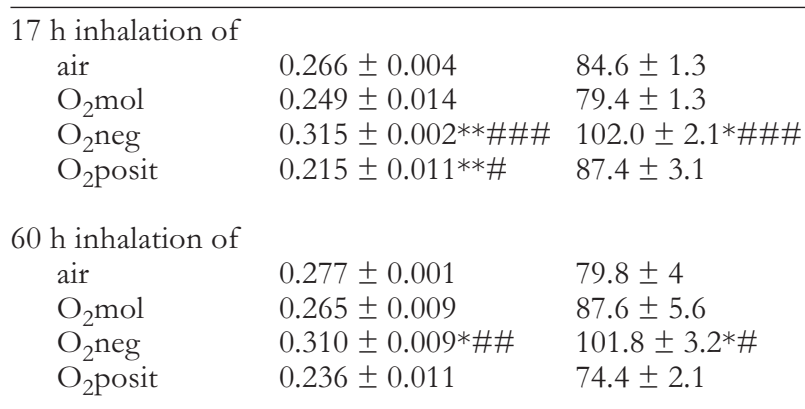

Values are given as means \pm SE of 5 experiments. ${ }^{*} \mathrm{p}<0.05$, $* * \mathrm{p}<0.01$

significantly different compared with the air treated group; $\# p<0.05$, \#\#p $<0.01$,

$\# \# \# p<0.001$ - significantly different compared with the $\mathrm{O}_{2}$ treated group.

To determine whether oxygenation treatments lead to increased oxidative damage to lipids, we measured the formation of conjugated dienes. While inhalation of molecular $\mathrm{O}_{2}$ was not accompanied by elevated lipid peroxidation, inhalation of partially negatively charged $\mathrm{O}_{2}$ caused significant changes (Table 1). When compared with the control guinea pigs, 17- and 60hour $\mathrm{O}_{2 \text { neg }}$ treatment increased conjugated dienes by 18.4 and $11.9 \%$, respectively. In contrast, $\mathrm{O}_{2}$ posit treatment prevented lipid peroxidation, after 17 -hour inhalation the level of conjugated dienes was significantly lower not only when compared with the animals which inhaled $\mathrm{O}_{2}$, but also those which inhaled atmospheric air. In order to determine whether lipid peroxidation products (LPO) can contribute to protein le-

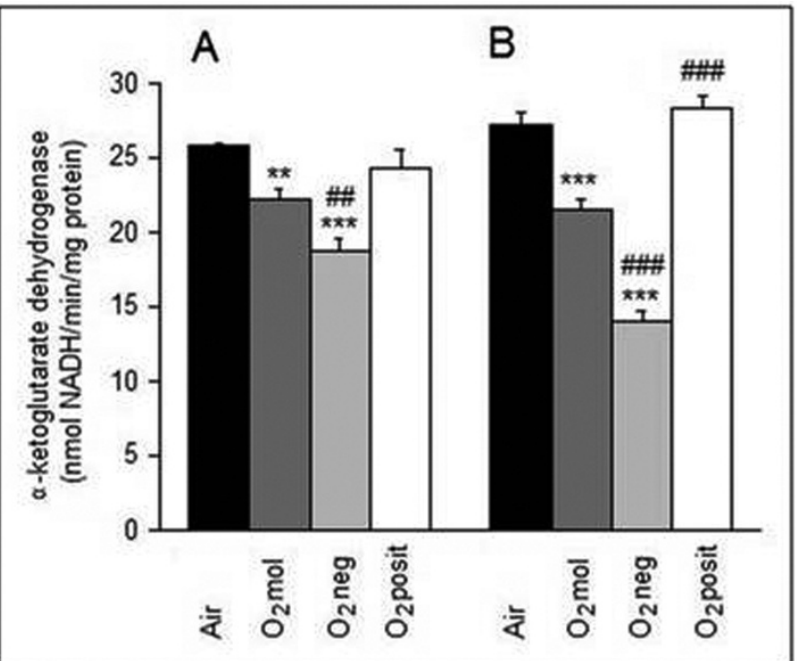

Fig. 3. Effects of $17 \mathrm{~h} \mathrm{(A)}$ and $60 \mathrm{~h}$ (B) oxygenation treatments on KGDH activity in guinea pig cardiac mitochondria. Values are means $\pm \mathrm{SE}$ of 5 experiments. $* * \mathrm{P}<0.01$, $* * * \mathrm{P}<0.001$ - significantly different compared with the airtreated group. \#\# $\mathrm{P}<0.01$, \#\#\# $\mathrm{P}<0.001$ - significantly different compared with the $\mathrm{O}_{2}$-treated group. sions, fluorescence spectra of conjugates formed from LPO end-products and proteins were measured. As expected, a significant rise in LPO product-protein conjugates was observed only in mitochondria isolated from $\mathrm{O}_{2 \text { neg }}$ treated guinea pigs (Table 1).

The effects of oxygen treatments on mitochondrial function were evaluated by measuring the activity of the KGDH complex. As shown in Fig. 3, individual oxygen treatments affected enzyme activity differently. Compared with the control guinea pigs, the activity was $13.7 \%(p<0.001)$ and $21.2 \%(p<0.001)$ lower in animals, which inhaled molecular $\mathrm{O}_{2}$ for 17 - and 60hours, respectively. Inhalation of $\mathrm{O}_{2}$ neg was associated with a more pronounced change in the activity, it decreased by $27.3 \%(\mathrm{p}<0.001)$ and $48.2 \%(\mathrm{p}<0.001)$ of the control level after 17- and 60-hour treatments, respectively. Moreover, these activities were also significantly lower when compared with the $\mathrm{O}_{2}$ treatment. In contrast, there were no significant changes in $\mathrm{KGDH}$ activity between the guinea pigs inhaling air and $\mathrm{O}_{2 \text { posit }}$.

\section{DisCUSSION}

In this study, long-term oxygenation was used as a model for the determination of ROS-induced oxidative damage. In addition to classical oxygenation, we studied the effects of inhalation of oxygen which was partially ionized in a high-voltage plasma chamber $[8$, 11]. Previous experimental and clinical studies have demonstrated beneficial effects of this therapy in comparison with inhalation of molecular oxygen $[7,8$, $11,12]$. Our results demonstrate that 17 - and 60 -hour inhalation of $100 \%$ oxygen is accompanied by increased oxidative damage to lipids and proteins and by loss in KGDH activity in mitochondria of the guinea pig heart. Free radical-induced oxidative damage and enzyme inhibition was even more pronounced when inhaled oxygen was partially negatively charged. On the other hand, when inhaled oxygen was partially positively charged, structural and functional changes were lowered or completely eliminated.

Our study shows that oxygenation treatment increases oxidative stress in mitochondria, which are known to be a major intracellular source of ROS/RNS and a vulnerable target of their damaging effects [13]. Accumulation of mitochondrial oxidative damage is in agreement with earlier study showing that a rise in partial pressure of $\mathrm{O}_{2}$ markedly increases $\mathrm{H}_{2} \mathrm{O}_{2}$ formation in isolated cardiac mitochondria [14]. To further understand the mechanism of oxygenationinduced mitochondrial injury, we examined the KGDH enzyme activity. This enzyme is essential for mitochondrial energy metabolism and other biological function, because it catalyses a critical step in the citric acid cycle that limits the amount of NADH available for respiratory chain [15] and regulates the level of the essential metabolite $\alpha$-ketoglutarate [16]. $\mathrm{KGDH}$ is known to be highly vulnerable to oxidative damage; it has been found to be inhibited by various ROS/RNS including $\mathrm{H}_{2} \mathrm{O}_{2}[17,18]$. Our study shows that a rise in partial pressure of $\mathrm{O}_{2}$ is associated with $\mathrm{KGDH}$ inhibition. The possible mechanisms by which inhalation of $\mathrm{O}_{2}$ mol could inactivate $\mathrm{KGDH}$ include oxida- 
tion of thiol groups or bityrosine formation, which were found to be significantly changed during the treatment. Analysis of KGDH composition revealed 32 moles of thiol groups per mol of enzyme and the absence of disulfide bridges [19]. It has been shown that thiol groups of the enzyme play a critical role in substrate binding and thiol-disulfide exchange can affect the activity [20]. There are no data in the literature on bityrosine formation in $\mathrm{KGDH}$ exposed to ROS, but nitration of tyrosine residues was shown to inhibit its activity [21]. It is then possible that other oxidative tyrosine lesions, including bityrosine formation, might also cause inhibition of KGDH.

In $\mathrm{O}_{2}$ neg treated guinea pigs inhibition of $\mathrm{KGDH}$ was much more pronounced than in $\mathrm{O}_{2}$ mol treated animals, although the changes in the contents of thiol groups and bityrosines were similar. These data suggest additional mechanism of $\mathrm{KGDH}$ inhibition during $\mathrm{O}_{2}$ neg treatment. In contrast to the other treatments, inhalation of partially negatively charged oxygen was accompanied by a significant rise in conjugated dienes, the markers of LPO., Reactive aldehydes, such as malondialdehyde and 4-hydroxynonenal (HNE), are generated during LPO and these compounds are potentially highly toxic for various cell components, particularly for proteins. Humphries and Szweda [22] have shown that incubation of cardiac mitochondria with HNE results in selective inhibition of KGDH and pyruvate dehydrogenase. We assessed a degree of modification of protein lysine residues by reactive aldehydes by measuring their fluorescence spectra. Our results show that the accumulation of fluorescent lysine derivatives occurs only in mitochondria from animals that inhaled $\mathrm{O}_{2 \text { neg. Thus, an indirect }}$ protein modification, mediated by LPO, might be the possible cause of a greater loss of $\mathrm{KGDH}$ activity in $\mathrm{O}_{2}$ neg compared with $\mathrm{O}_{2}$ mol-treated animals. Since $\mathrm{KGDH}$ is a rate-limiting enzyme of oxidative phosphorylation, its inhibition is likely associated with impairment of heart energy metabolism and subsequently heart function. In this respect, our findings that inhalation of $\mathrm{O}_{2}$-enriched with positively charged $\mathrm{O}_{2}$ is accompanied by preservation of KGDH activity is of considerable importance. Diminished oxidative lesions in mitochondrial lipids and proteins suggest that elimination of ROS/RNS is a likely mechanism of $\mathrm{O}_{2}$ pos protective effects. These data suggest that $\mathrm{O}_{2 \text { pos }}$ oxygenation can be an alternative to antioxidant supplementation, whose efficiency to prevent oxidative damage caused by oxygen therapy is not unequivocal.

In conclusion, our study provides evidence that oxygenation treatment is associated with oxidative stress and loss of $\alpha$-ketoglutarate dehydrogenase activity in mitochondria of the guinea pig heart. These adverse effects were prevented when inhaled oxygen was partially positively charged. Our findings support the view that ionized oxygenation optimizes the effect of oxygen therapy.

Acknowledgements: This work was partially supported by grants VEGA 1/0027/08 and VVCE APVV 0064/07 from the Ministry of Education and Science of the Slovak Republic.

Conflicts of interest: Authors had no conflicts of interest.

\section{REFERENCES}

[1] Dekleva M, Neskovic A, Vlahovic A, Putnikovic B, Beleslin B, Ostojic M. Adjunctive effect of hyperbaric oxygen treatment after thrombolysis on left ventricular function in patients with acute myocardial infarction. Am Heart J 2004; 148: E14.

[2] Thom SR. Oxidative stress is fundamental to hyperbaric oxygen therapy. J Appl Physiol 2009; 106: 988-995.

[3] Colantuono G, Tiravanti EA, Di Venosa N, Cazzato A, Rastaldo R, Cagiano R, D'Agostino D, Federici A, Fiore T. Hyperoxia confers myocardial protection in mechanically ventilated rats through the generation of free radicals and opening of mitochondrial ATP-sensitive potassium channels Clin Exp Pharmacol Physiol 2008; 35: 64-71.

[4] Dundar K, Topal T, Ay H, Oter S, Korkmaz A. Protective effects of exogenously administrated or endogenously produced melatonin on hyperbaric oxygen-induced oxidative stress in the rat brain. Clin Exp Pharmacol Physiol 2005; 32: 926-930.

[5] Brozmanova M, Plevkova J, Bartos V, Plank L, Javorka M, Tatar M. The interaction of dietary antioxidant vitamins and oxidative stress on cough reflex in guinea-pigs after long term oxygen therapy J Physiol Pharmacol 2006; 57 (Suppl 4): 45-54.

[6] Bader N, Bosy-Westphal A, Koch A, Rimbach G, Weimann A, Poulsen HE, Müller MN. Effect of hyperbaric oxygen and vitamin $\mathrm{C}$ and $\mathrm{E}$ supplementation on biomarkers of oxidative stress in healthy men. Br J Nutr 2007; 98: 826-833.

[7] Calkovska A, Engler I, Mokra D, Drgova A, Sivonova M, Tatarkova Z, Calkovsky V, Brozmanova M, Tatar M . Differences in oxidative status, lung function, and pulmonary surfactant during long-term inhalation of medical oxygen and partially ionized oxygen in guinea pigs. J Physiol Pharmacol 2008; 59 (Suppl 6): 173-181.

[8] Engler I, Atzmüller Ch, Donic V, Hainschwang, W, Jutka $\mathrm{K}$, Steinhäusler F. Application of reactive oxygen species and biotonometry as a new approach to cancer. Folia Biol (in press).

[9] Nulton-Persson AC, Szweda LI. Modulation of mitochondrial function by hydrogen peroxide. J Biol Chem 2001; 276: 23357-23361.

[10] Kaplan P, Babusikova E, Lehotsky J, Dobrota D. Free radical-induced protein modification and inhibition of Ca2+-ATPase of cardiac sarcoplasmic reticulum. Mol Cell Biochem 2003; 248: 41-47.

[11] Engler I. Ionisierter Sauerstoff. Uelzen, ML Verlag, 1988.

[12] Pohl P, Engler-Plörel S, Engler I. Inhalationstherapie mit IO2Th bei patienten mit chronisch progredienter multipler sklerose. Erfahrungsheilkunde, 1992; 1: 46-48.

[13] Hool LC. Reactive oxygen species in cardiac signaling: from mitochondria to plasma membrane ion channels. Clin Exp Pharmacol Physiol 2006; 33: 146-151.

[14] Boveris A, Chance B. The mitochondrial generation of hydrogen peroxide. General properties and effect of hyperbaric oxygen. Biochem J 1973; 134: 707-716.

[15] Sheu KF, Blass JP. The $\alpha$-ketoglutarate dehydrogenase complex. Ann NY Acad Sci 1999; 893: 61-78.

[16] Harrison AP, Pierzynowski SG. Biological effects of 2 oxoglutarate with particular emphasis on the regulation of protein, mineral and lipid absorption/metabolism, muscle performance, kidney function, bone formation and cancerogenesis, all viewed from a healthy ageing perspective state of the art-review article. J Physiol Pharmacol 2008; 59: 91-106.

[17] Tretter L, Adam-Vizi V. Inhibition of Krebs cycle enzymes by hydrogen peroxide: a key role of $\alpha$-ketoglutarate dehydrogenase in limiting NADH production under oxidative stress. J Neurosci 2000; 20: 8972-8979. 
[18] Applegate MAB, Humphries KM, Szweda LI. Reversible inhibition of $\alpha$-ketoglutarate dehydrogenase by hydrogen peroxide: glutathionylation and protection of lipoic acid. Biochemistry 2008; 47: 473-478.

[19] Koike K, Hamada M, Tanaka N, Otsuka K-I, Ogasahara K, Koike M. Properties and subunit composition of the pig heart 2-oxoglutarate dehydrogenase. J Biol Chem 1973; 249: 3836-3842.

[20] Bunik VI, Buneeva OA, Gomazkova VS: Regulation of alpha-ketoglutarate dehydrogenase cooperative properties in substrate binding by thiol-disulfide exchange. Biochem Int 1990; 21: 873-881.

[21] Park LCH, Zhang H, Sheu KF, Calingasan NY, Kristal BS, Lindsay JG, Gibson GE. Metabolic impairment induces oxidative stress, compromises inflammatory responses, and inactivates a key mitochondrial enzyme in microglia. J Neurochem 1999; 72: 1948-1958.
[22] Humphries KM, Szweda LI. Selective inactivation of $\alpha$ ketoglutarate dehydrogenase and pyruvate dehydrogenase: reaction of lipoic acid with 4-hydroxy2-nonenal. Biochemistry 1998; 37: 15835-15841.

Corresponding author:

Prof. Peter Kaplan, Ph.D.

Department of Medical Biochemistry

Jessenius Faculty of Medicine

Comenius University

Mala Hora 4,

SK-036 01 Martin, Slovakia

Phone: +421-43-4131565

Fax: +421-43-4136770

E-mail: Kaplan@jfmed.uniba.sk 